\title{
A gestão municipal de resíduos sólidos e as ações de sustentabilidade: um estudo realizado em um município do centro oeste do Paraná
}

\author{
Management municipal solid waste and sustainability actions: a study done on \\ a city of the Midwest of Paraná State
}

Caroline Monteiro, Josiani Aparecida Karpinski, Marcos Roberto Kuhl, João Francisco Morozini

Universidade Estadual do Centro Oeste (UNICENTRO), Guarapuava, Paraná, Brasil

\section{Resumo}

O objetivo deste estudo foi identificar e analisar aspectos da sustentabilidade na gestão municipal de resíduos sólidos em um município do Centro Oeste do Paraná. A pesquisa caracteriza-se como um estudo de caso de caráter descritivo e com escopo quantitativo. A coleta de dados, que ocorreu no mês de novembro de 2014, se deu por meio da aplicação de questionário estruturado, disponibilizado eletronicamente. A pesquisa contou com uma amostra de 59 munícipes, caracterizada por estudantes de ensino superior, gestores, servidores e técnicos da área ambiental de um município localizado na região Centro Oeste do Paraná, os quais responderam 45 questões relacionadas às dimensões da sustentabilidade. Identificaram-se alguns dos aspectos da sustentabilidade na gestão municipal de resíduos sólidos, verificando que existem entre os respondentes dois grupos com percepções distintas sobre estes aspectos. Desta maneira, é possível supor que os aspectos da sustentabilidade, na gestão municipal de resíduos sólidos do município, ainda não estão perfeitamente alinhados com as demais dimensões ou que talvez estejam alinhados, mas ainda não de conhecimento de toda população, limitado a amostra.

Palavras-chave: Sustentabilidade. Resíduos sólidos. Gestão pública.

\section{Abstract}

The objective of this study was to identify and analyze aspects of sustainability in municipal solid waste management in a city of the midwest of Paraná State. The research is characterized as a descriptive and quantitative study. Data collection, which happen in November 2014, through a questionnaire structured available electronically. The survey included a sample of 59 citizens, characterized by students in higher education, managers, servers and technicians in the environmental area, a municipality located in the region west of the Parana Center, who answered 45 questions related to the dimensions of sustainability. They identified some of the aspects of sustainability in municipal solid waste management, checking that exist between respondents two groups with different perceptions about these aspects. Thus, it is possible to assume that the aspects of sustainability in municipal management of municipal solid waste are not perfectly aligned with other dimensions or who may be aligned, but still not aware of the whole population, limited to the sample.

Keywords: Sustainability. Solid waste. Public management.

CM é professora, mestre em Administração, e-mail: kcarolmonteiro@gmail.com

JAK é contadora, mestre em Administração, e-mail: jhosyk@gmail.com

MRK é professor, pós doutor em Contabilidade, e-mail: marcosrobertokuhl@hotmail.com

JFM é professor, pós doutor em Administração de Empresas, e-mail: jmorozini@uol.com.br 


\section{Introdução}

A movimentação em prol do desenvolvimento sustentável parece ser um dos movimentos sociais mais importantes deste início de século e milênio (Barbieri et al., 2010). A noção de sustentabilidade possui uma longa história intelectual, ou seja, há a necessidade de uma volta ao conceito de economia estacionária ou estado estacionário, empregado por economistas do século XIX, o chamado equilíbrio entre a produção e os recursos naturais. Mill (1876) acreditava que as pessoas iriam se conscientizar e contentar-se com o estacionário sem que a necessidade os obrigasse a isso. Já no século XX, a noção de sustentabilidade foi ampliada para abranger outros aspectos da questão ambiental, como a relação com o mundo dos vivos (natureza) e da poluição (Daly, 1973; Iucn, 1980; Goodland, 1995).

Assim, o grande avanço da tecnologia aponta nas organizações a necessidade de processos de reestruturação ao investir tanto para melhorar a qualidade de seus produtos e serviços quanto para melhorar sua imagem perante a sociedade, garantindo, assim, sua posição de destaque em um mercado altamente competitivo (Maia, 2007).

Na sociedade atual, os valores ligados ao desenvolvimento sustentável e ao respeito às políticas ambientais têm sido institucionalizados em maior ou menor grau nos diversos países pela mídia, pelos movimentos sociais e ambientalistas, e pelos governos. Como resposta a essas pressões institucionais, surgem novos modelos organizacionais [...] (Barbieri et al., 2010, p. 149).

Por isso, a escolha do tema justifica-se pelo fato de que as ações de sustentabilidade estão sendo operacionalizadas pelos municípios por meio de programas que integram o sistema de gerenciamento de resíduos sólidos domiciliares no Brasil. No âmbito social, a pesquisa permitirá maiores conhecimentos à comunidade sobre as ações de sustentabilidade ao evidenciar as atividades que estão sendo desenvolvidas no município, junto à sociedade; haja vista que a crescente produção de resíduos sólidos preocupa cada vez mais os pequenos municípios, seja na questão ambiental, social e também econômica, quando se refere à destinação dos resíduos sólidos.

Os municípios, em sua maioria, utilizam um sistema tradicional de coleta de resíduos sólidos residenciais em que há veículos que recolhem os resíduos em recipientes abertos ou fechados, sem triagem de seu conteúdo. Todavia, devido ao apelo às práticas ambientais politicamente corretas, originou-se uma tendência da utilização do sistema de coleta seletiva no qual os resíduos sólidos são selecionados por categorias (Rodrigues \& Santana, 2012).

A coleta seletiva, além de contribuir significativamente para sustentabilidade urbana, vem incorporando gradativamente um perfil de inclusão social e geração de renda para os setores mais carentes e excluídos do acesso aos mercados formais de trabalho (Singer, 2002). Sendo assim, o ser humano deve conscientizar-se sobre a necessidade de adotar um comportamento mais prudente em relação ao meio ambiente e, também, fazer o uso de seus recursos com parcimônia (Barbieri, 2007).

Neste sentido, apresentou-se o seguinte questionamento de pesquisa: Como aspectos da sustentabilidade são/estão sendo inseridos na gestão municipal de resíduos sólidos em um município do Centro Oeste do Paraná?

Para tanto, o objetivo geral desta pesquisa foi identificar e analisar aspectos da sustentabilidade na gestão municipal de resíduos sólidos em um município do Centro Oeste do Paraná. E os objetivos específicos definidos foram: a) identificar, junto aos estudantes do ensino superior, qual o impacto das ações de sustentabilidade em um município do Centro Oeste do Paraná; b) verificar como ocorre o processo de implantação das ações de sustentabilidade em um município do Centro Oeste do Paraná; c) analisar a importância de ações bem sucedidas junto ao desenvolvimento do município.

Nesta perspectiva, este estudo aborda o tema às ações que podem contribuir para a geração de indicadores de sustentabilidade, desenvolvido em um município do Centro Oeste do Paraná.

\section{Sustentabilidade}

O meio ambiente é um tema que conquistou espaço evidente nas ruas, nos auditórios, na imprensa, ademais, compõe o vocabulário de políticos, empresários, administradores, líderes sindicais, dirigentes de organizações não governamentais e cidadãos de uma maneira geral. Contudo, essa preocupação ainda não se transformou em reais práticas administrativas, pois é notório o acúmulo de problemas ambientais que coloca em risco a vida de todos os seres vivos (Barbieri, 2007). 
A crença de que a natureza existe para servir o ser humano contribuiu para o estado de degradação ambiental que hoje se observa. Percebe-se que o aumento da escala de produção e consumo contribuiu para os problemas ambientais hoje existentes (Barbieri, 2007). Neste sentido, é necessário que exista uma conscientização por parte da sociedade para que as medidas sustentáveis adotadas sejam eficazes.

Ao buscar na literatura uma definição de sustentabilidade, observa-se que não há um conceito único, mas abordagens comuns entre os autores que tratam desta temática. Elkington (2001, p. 20), a define como "princípio que assegura que nossas ações de hoje não limitarão a gama de opções econômicas, sociais e ambientais disponíveis para as futuras gerações". Sendo assim, sustentabilidade, de forma ampla, refere-se ao modo implícito, à manutenção (sustentar) da capacidade de produção de bens e serviços (Candler \& Dumont, 2012).

Nesta perspectiva, o desenvolvimento sustentável deve ser capaz de contribuir para a solução dos problemas atuais e da garantia da vida, por meio da proteção e da manutenção dos sistemas naturais que a tornam possível. Por isso, fazem-se necessárias mudanças profundas nos sistemas de produção, organização da sociedade humana e utilização de recursos naturais indispensáveis à vida no nosso planeta (Reis et al., 2005).

\section{Indicadores de sustentabilidade}

Os indicadores são instrumentos que possibilitam medir a distância entre o quadro atual de uma sociedade e seus objetivos de desenvolvimento, ao mesmo tempo em que oferece subsídios à formulação e práticas de políticas (Guimarães \& Feichas, 2009). Desta maneira, um indicador é mais que uma estatística (Martínez, 2006).

Polaz \& Teixeira (2009) agruparam as dimensões da sustentabilidade em relação a problemas selecionados pelos gestores públicos, como prioridade para gestão de resíduos sólidos urbanos, em cinco categorias: dimensão ambiental/ecológica, econômica, social, política/institucional e cultural (Quadro 1):

\section{Gestão de resíduos sólidos}

Atualmente, a política da gestão de resíduos sólidos é bastante complexa em sua essência, só pode ser considerada eficaz quando os resíduos são geridos de forma consistente, de forma a contemplar questões relacionadas ao ciclo de vida do produto, ou seja, a minimização do uso dos recursos da natureza e a não geração dos resíduos (Agamuthu, et al., 2009).

0 aumento considerável na geração de resíduos deve-se ao fato do acesso facilitado a diversos produtos e a obsolescência acelerada, ocasionada pelos avanços tecnológicos constantes, o que leva a população a descartar em maior quantidade e, muitas vezes, precocemente diversos objetos/aparelhos (Philippi Jr., et al., 2012). Nesta perspectiva, Ferreira e Ferreira (2008) afirmam que o processo acelerado de urbanização tende ao aumento do consumo de bens não duráveis crescendo, assim, também a quantidade de lixo gerado tanto nos grandes quando nos pequenos municípios.

Sendo assim, a implantação da gestão integrada de resíduos leva os governos, a empresas, os cidadãos e a sociedade em geral a necessárias mudanças culturais e padrões comportamentais face aos resíduos (Philippi Jr., et al., 2012).

\section{A Gestão Pública e a Sustentabilidade}

Atualmente, os gestores públicos não possuem somente o papel de decidir sobre as melhores políticas e conduzir a sua implementação; precisam, também, cuidar da construção dos interesses gerais, exercendo a interação com vários grupos de interesse e firmando laços de confiança (Andion, 2012).

Ademais, mais do que o alcance de objetivos e controle de comportamentos, o gestor público necessita dialogar e estabelecer confiança entre os diversos atores que compõem a esfera pública, visando a promoção do interesse público (Andion, 2012).

Para tanto, as legislações vigentes devem ser respeitadas, os direitos das populações locais devem ser garantidos, o ambiente natural e sua biodiversidade devem ser conservados, o patrimônio cultural e valores locais devem ser considerados juntamente com o estímulo do desenvolvimento social e econômico das cidades (Corrêa et al., 2010).

Neste sentido, a participação popular é primordial, pois a comunidade é que direciona a sustentabilidade local, ou seja, a comunidade precisa estar inteiramente sensibilizada de que essa atividade é uma alternativa de desenvolvimento e de prosperidade, bem como um importante elemento de inclusão social com a geração de emprego e renda nas próprias localidades (Corrêa et al., 2010). 
Quadro 1- Dimensões da sustentabilidade

\begin{tabular}{|c|c|}
\hline & 1. Dimensão ambiental/ecológica \\
\hline \multirow{2}{*}{ 1. Impactos ambientais associados aos RSU } & 1.1.a. Presença de RSU nas vias e terrenos públicos/privados \\
\hline & 1.1.b. Existência de passivo ambiental (antigos lixões) \\
\hline 2. Licenciamento ambiental & 1.2.a. Morosidade do processo de aprovação, licenciamento e construc̦ão de aterros sanitários \\
\hline 3. Economia de recursos naturais renováveis e não renováveis & 1.3.a. Insuficiência ${ }^{\star}$ dos processos de recuperação de resíduos (reaproveitamento, reciclagem e/ou compostagem) \\
\hline \multicolumn{2}{|r|}{ 2. Dimensão econômica } \\
\hline 1. Recursos financeiros e eficiência da gestão de RSU & 2.1.a. Ausência de fontes específicas de recursos para a gestão de RSU (autofinanciamento) \\
\hline 2. Geração de trabalho e renda & Não houve problemas selecionados como prioridade nesta categoria \\
\hline \multicolumn{2}{|r|}{ 3. Dimensão social } \\
\hline 1. Universalização dos serviços de RSU & Não houve problemas selecionados como prioridade nesta categoria \\
\hline 2. Condições do trabalho nas atividades associadas aos RSU & Não houve problemas selecionados como prioridade nesta categoria \\
\hline \multirow{3}{*}{ 3. Valorização social das atividades relacionadas aos RSU } & 3.3.a. Insuficiência de políticas públicas específicas para catadores de resíduos recicláveis \\
\hline & 3.3.b. Cadeia produtiva informal ignorada pelo poder público \\
\hline & 3.3.c. Dificuldades de acesso a benefícios sociais de natureza pública (como educação, saúde) \\
\hline & 4. Dimensão política/institucional \\
\hline \multirow[b]{2}{*}{ 1. Institucionalização da gestão de RSU } & 4.1.a. Ausência de organograma e de plano de carreira para o setor de RSU \\
\hline & $\begin{array}{l}\text { 4.1.b. Recursos humanos/pessoal inadequado/insatisfatório (quantidade, capacitação, estruturação) } \\
\text { 4.1.c. Falta de fiscalização ambiental e aplicação da legislação pertinente }\end{array}$ \\
\hline \multirow{4}{*}{ 2. Execução da gestão de RSU } & 4.2.a. Sistema operando de modo deficitário e/ou inadequado \\
\hline & 4.2.b. Capacidade instalada de operação super/subestimada \\
\hline & 4.2.c. Insuficiência de infraestrutura e equipamentos (caminhões compactadores, tratores, balanças, esteiras etc.) \\
\hline & 4.2.d. Obsolescência ou falta de manutenção/renovação de estruturas e equipamentos \\
\hline 3. Participação da sociedade na gestão de RSU & Não houve problemas selecionados como prioridade nesta categoria \\
\hline \multicolumn{2}{|r|}{ 5. Dimensão cultural } \\
\hline 1. Geração de RSU & $\begin{array}{l}\text { 5.1.a. Insuficiência de programas educativos continuados voltados à questão da minimização da geração e do } \\
\text { gerenciamento adequado dos RSU }\end{array}$ \\
\hline 2. Valores e atitudes da sociedade em relação aos RSU & 5.2.a. Insuficiência de atividades de multiplicação de boas práticas em relação aos RSU \\
\hline
\end{tabular}

Fonte: Polaz \& Teixeira $(2009$, p. 413).

Contudo, não somente um conjunto de ações concretas coletiva e organizadamente desenvolvidas, a gestão pública necessita também da condição de estabelecimento de bases normativas que deem suporte para que as decisões coletivas sejam institucionalizadas (Philippi Jr. et al., 2012).

\section{Contexto de pesquisa}

A pesquisa aplicou-se no município de Candói, localizado na região Centro Oeste do estado do Paraná (Figura 1).

Criado em 27 de agosto de 1990, pela Lei Estadual no 9.553, teve o território desmembrado da cidade de
Guarapuava-PR em 01/01/1993. 0 Município possuiárea territorial de $1.509,059 \mathrm{~km}^{2}$, situado aproximadamente a $324 \mathrm{~km}$ da capital do Estado. De acordo com a classificação referente à atividade, o ramo de maior expressividade refere-se a agropecuária, seguido da indústria e, por último, serviços e administração pública (IPARDES, 2015).

A população estimada em 2015 é de 15.822 habitantes, característica típica de um município de pequeno porte. 0 Índice de desenvolvimento humano (IDH) apresentado em 2010, igual a 0,635 , considerado médio pelos critérios do Instituto Paranaense de Desenvolvimento Econômico e Social - Ipardes. Conforme este instituto, o IDH que apresenta variação de 0 (zero) a 1 (um) possui as seguintes faixas de desenvolvimento 


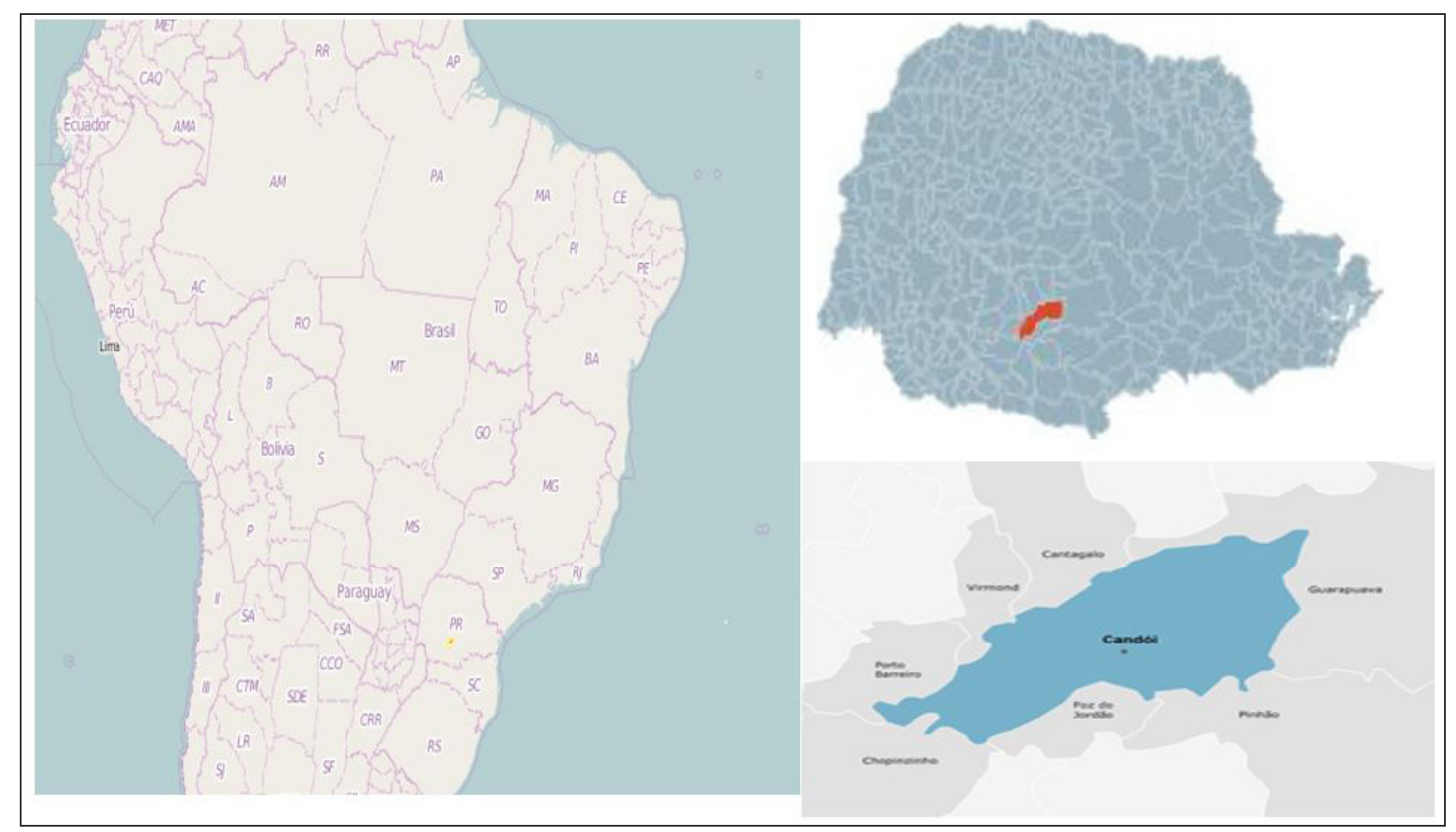

Figura 1 - Localização geográfica de Candói, Paraná, Brasil Fonte: Ipardes (2015), IBGE (2015).

humano municipal: 0,000 a 0,499 - muito baixo; 0,500 a 0,599 - baixo; 0,600 a 0,699 - médio; 0,700 a 0,799 - alto e 0,800 e mais - muito alto, assim, quanto mais próximo a 1 maior seria a qualidade de vida deste local (IPARDES, 2015). Outro dado importante é que o índice apresentado pelo Candói também se encontra abaixo do índice de 0,749 , medido para o Estado no mesmo período.

Quanto à População Economicamente Ativa (PEA) observa-se que 6.905 pessoas (menos de $44 \%$ da população municipal) encontram-se inseridas no mercado de trabalho ou estão procurando se inserir nele. Já de acordo com o índice de Gini (o qual refere-se a uma medida do grau de concentração de uma distribuição, cujo valor varia de zero - o qual representa a perfeita igualdade, até um - que representa a desigualdade máxima), em 2010 o município obteve um alto grau de desigualdade: 0,5476 resultando nas diferenças entre os rendimentos das pessoas mais ricas e as mais pobres e a renda média domiciliar apresentada em 2010 era de $\mathrm{R} \$ 462,51$ (abaixo do salário mínimo que no período era de $\mathrm{R} \$ 510,00$ ) (IPARDES, 2015).

\section{Procedimentos metodológicos}

Diante do objetivo proposto, esta pesquisa classifica-se como descritiva que, conforme Collis \& Hussey (2005), é utilizada na identificação e obtenção de informações sobre as peculiaridades de um determinado fato. A natureza descritiva foi utilizada para relatar sobre os fenômenos que se relacionam aos aspectos da sustentabilidade na gestão municipal de resíduos sólidos, em um município do Centro Oeste do Paraná.

A estratégia de pesquisa adotada foi o estudo de caso que, de acordo com Yin (2010), trata-se de uma inquirição empírica a qual investiga um fenômeno contemporâneo dentro de um contexto da vida real. Trata-se de um estudo de caso por abordar aspectos da sustentabilidade na gestão municipal de resíduos sólidos em um município específico do Centro Oeste do Paraná.

Quanto aos meios de investigação, foram utilizados dados primários e, quanto à análise, a pesquisa é caracterizada como quantitativa, pois tenta fazer uma mensuração precisa de algo (Cooper \& Schindler, 2011). Desta forma, como técnica de coleta de dados, optou-se pela aplicação de questionários com preenchimento online, composto por 45 questões fechadas, por meio da utilização da escala Likert de sete pontos, que possibilita escala de medida, solicitando que o entrevistado indique seu grau de concordância ou não em relação a um objeto, sendo mais comumente usada para medir atitudes e opiniões (Botelho e Zouain, 2009).

0 universo constituiu-se de quatrocentos munícipes, caracterizados em estudantes de ensino superior, gestores, servidores e técnicos da área ambiental de 
um município localizado na região Centro Oeste do Paraná. Tais sujeitos de pesquisa foram selecionados devido ao fato de serem a parcela da população a qual compõe uma associação municipal que desenvolve um projeto de conscientização da coleta seletiva. 0 número total da amostra foi de 59 respondentes, ou seja, totalizou $14,7 \%$ do universo de pesquisa.

A coleta de dados ocorreu no mês de novembro de 2014. Aplicou-se à amostra, um questionário online, via Google Docs, sem pretensão de identificar o autor das respostas, ademais, tiveram uma introdução explicativa para facilitar o preenchimento, pois os pesquisadores não estavam presentes neste momento.
O instrumento de pesquisa foi elaborado a partir do referencial teórico, cujo modelo é composto pelas dimensões da sustentabilidade, escolhidos a partir do resgate teórico dos autores: Dias (2003); Furiam \& Günther (2006); Polaz \& Teixeira (2009); Pereira (2010); Moraes \& Borja (2003) e; Santiago \& Dias (2010), utilizados na validação do protocolo de estudo de caso, conforme o Quadro 2.

No que diz respeito à fase da análise de dados, foram utilizadas as técnicas estatísticas alicerçadas na estatística descritiva, por meio da utilização do pacote estatístico Statistical Package for the Social Sciences $\left(\mathrm{SPSS}^{\circledR}\right)$.

Quadro 2 - Dimensões da Sustentabilidade a partir da literatura

\begin{tabular}{|c|c|}
\hline Dimensões & Características \\
\hline Política/Institucional & $\begin{array}{l}\text { - Implementação de politicas públicas específicas para catadores de resíduos sólidos urbanos; } \\
\text { - Constante preocupação do poder público com os catadores autônomos; } \\
\text { - Participaccão efetiva dos serviços públicos municipais no tratamento da coleta seletiva; } \\
\text { - Existência do programa cidade limpa; } \\
\text { - Existência de uma escala de dias da realização da coleta. }\end{array}$ \\
\hline Tecnológica/Estrutural & $\begin{array}{l}\text { - Existência de estrutura física adequada para a separacão dos materiais recicláveis; } \\
\text { - Existência de estrutura de coleta adequada (caminhões compactadores, tratores, balanças). }\end{array}$ \\
\hline Econômica/Financeira & $\begin{array}{l}\text { - Promoccão da geração de renda familiar por meio da coleta de resíduos sólidos urbanos (catadores de lixo); } \\
\text { - Incentivo à empregabilidade sustentável - desenvolvimento profissional sustentável, capaz de se adaptar conforme as necessidades do mercado. }\end{array}$ \\
\hline Ecológica/Ambiental & $\begin{array}{l}\text { - Manutenção de lixões; } \\
\text { - Existência de resíduos sólidos urbanos nas vias e terrenos públicos/privados; } \\
\text { - Redução do tempo para liberação licenciamento ambiental; } \\
\text { - Ocorrência contumaz de contaminação de solo e/ou água com produtos tóxicos; } \\
\text { - Fiscalização ambiental regular; } \\
\text { - Efetiva aplicação da legislação ambiental; }\end{array}$ \\
\hline Conhecimento/Cultural & 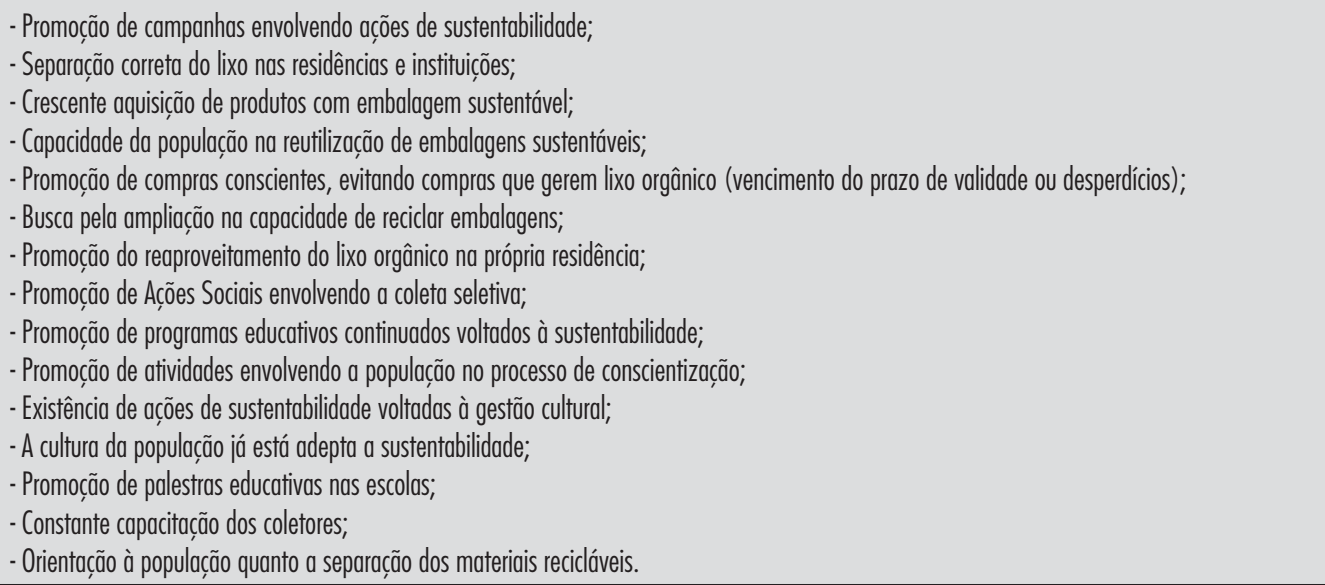 \\
\hline Inclusão Social & $\begin{array}{l}\text { - Busca por melhores condições de trabalho nas atividades dos catadores de resíduos sólidos urbanos; } \\
\text { - Promoção da valorizaccão social das atividades desempenhadas pelos catadores de resíduos sólidos urbanos; } \\
\text { - Constante preocupação do poder público com a cadeia produtiva informal; } \\
\text { - Existência de incentivo aos catadores em manter os filhos na escola; } \\
\text { - Existência de ações sociais envolvendo a comunidade acadêmica; } \\
\text { - Adesão da população às aç̦ôes de sustentabilidade. }\end{array}$ \\
\hline
\end{tabular}

Fonte: Elaborado pelos autores a partir dos estudos de Dias (2003), Furiam \& Günther (2006), Polaz \& Teixeira (2009), Pereira (2010), Moraes \& Borja (2003) e Santiago \& Dias (2010). 


\section{Apresentação e análise dos resultados}

A seguir apresentam-se os resultados desta pesquisa. A estrutura está disposta da seguinte maneira: idade, estado civil e gênero; grau de escolaridade; área de atuação profissional e renda familiar mensal e o grau de importância da sustentabilidade na vida pessoal e profissional.

\section{Perfil dos respondentes}

A Tabela 1 apresenta os dados referentes ao perfil dos estudantes pesquisados. A questão $1 \mathrm{faz}$ referência à idade, a questão 2 ao estado civil e a questão 3 ao gênero.

Por meio da Tabela 1 observa-se que, na amostra pesquisada, há o predomínio de jovens (idade entre

Tabela 1 - Perfil dos estudantes pesquisados

\begin{tabular}{clcc}
\hline \multicolumn{1}{c}{ Variável } & \multicolumn{1}{c}{ Escala } & N & \% \\
\hline \multirow{4}{*}{ Idade } & 18 a 25 anos & 19 & $32 \%$ \\
& 26 a 33 anos & 28 & $47 \%$ \\
& 34 a 41 anos & 7 & $12 \%$ \\
& Acima de 41 anos & 5 & $9 \%$ \\
\hline \multirow{3}{*}{ Estado civil } & Solteiro(a) & 24 & $41 \%$ \\
& Casado(a) & 20 & $34 \%$ \\
& Viúvo(a) & 1 & $2 \%$ \\
& União Estável & 10 & $16 \%$ \\
\multirow{2}{*}{ Gênero } & Outro & 4 & $7 \%$ \\
& Masculino & 30 & $51 \%$ \\
\hline
\end{tabular}

Fonte: Elaborado pelos autores com dados coletados na pesquisa de campo (2014)

Tabela 2 - Grau de escolaridade

\begin{tabular}{clcc}
\hline Variável & \multicolumn{1}{c}{ Escala } & N & $\%$ \\
\hline \multirow{4}{*}{ Grau } & Nõo estuda & 5 & $9 \%$ \\
& Ensino médio & 2 & $3 \%$ \\
& $\begin{array}{l}\text { Graduacão } \\
\text { Especializacão (pós graduacão,o, } \\
\text { mestrado, doutorado) }\end{array}$ & 42 & $71 \%$ \\
\hline
\end{tabular}

Fonte: Elaborado pelos autores com dados coletados na pesquisa de campo (2014)
18 e 33 anos), representando 79\% do total dos respondentes, e apenas $21 \%$ têm acima de 34 anos de idade.

Em relação ao estado civil, $41 \%$ são solteiros, $34 \%$ casados e os outros $25 \%$ representam as outras variáveis. Quanto ao gênero, o predominante foi o masculino com $51 \%$, pequena diferença para o gênero feminino com $49 \%$ dos respondentes.

Na Tabela 2, apresenta-se o grau de escolaridade dos pesquisados.

Conforme pode ser verificado, $88 \%$ dos pesquisados estão no nível de terceiro grau de escolaridade, apenas $9 \%$ não estuda e $3 \%$ estão ainda no ensino médio.

No que diz respeito à área de atuação profissional, apresentado na Figura 2, é possível verificar o que segue:

A Figura 2 demonstra que a área de atuação profissional dos pesquisados predominante é a área pública.

Já na Figura 3 apresentam-se os fatores econômicos relacionados à renda familiar mensal dos pesquisados, conforme segue:

Na Figura 3, a representatividade da renda familiar, predomina a renda mensal de 2.500 a $3.000,00$ reais mensais. Com base na teoria é possível afirmar que a qualidade de vida está relacionada com os padrões de desenvolvimento social, neste sentido a noção de sustentabilidade implica, portanto, uma inter-relação necessária de justiça social, qualidade de vida, equilíbrio ambiental e a ruptura com o atual padrão de desenvolvimento (Jacobi, 1997).

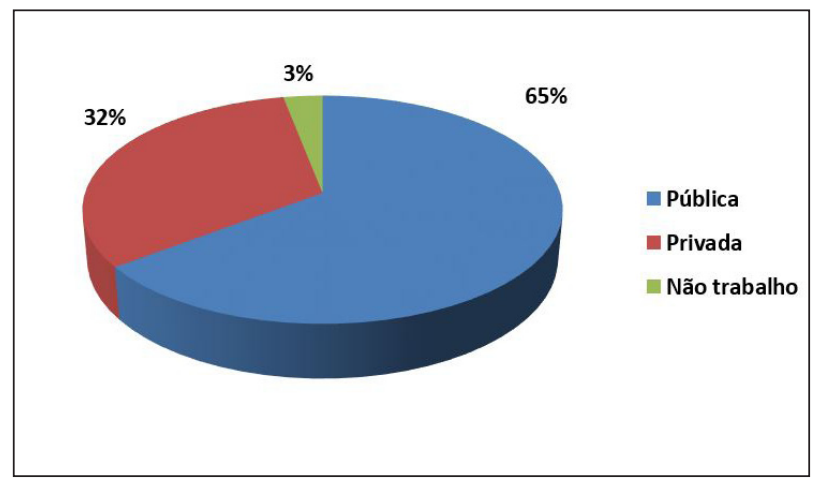

Figura 2 - Área de atuação profissional

Fonte: Elaborado pelos autores com dados coletados na pesquisa de campo (2014). 


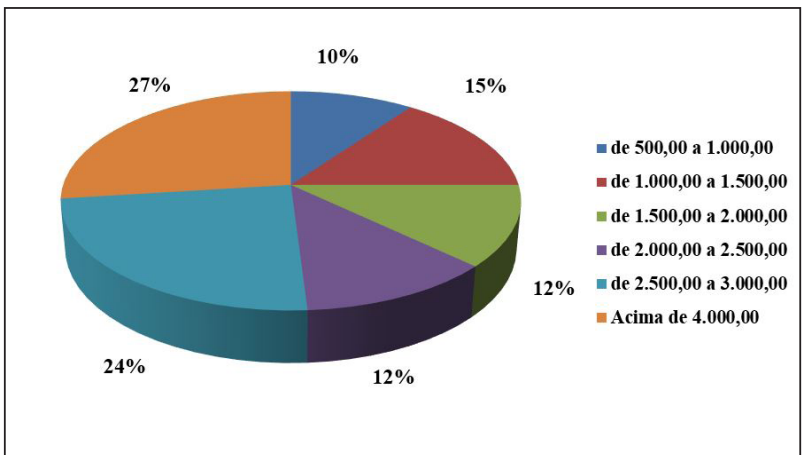

Figura 3 - Renda familiar mensal

Fonte: Elaborado pelos autores com dados coletados na pesquisa de campo (2014).

\section{Abordagem sobre a sustentabilidade}

A gestão municipal de Resíduos Sólidos do município pesquisado é compartilhada pela Secretaria Municipal de Obras, Serviços Públicos e Transportes (limpeza urbana, coleta de galhos, restos de construção civil e entulhos) e pela Secretaria Municipal de Turismo e Meio Ambiente (assessoria ao programa de coleta seletiva, responsável pelos caminhões de coleta e gestão de resíduos sólidos do município e desenvolvimento de campanhas de educação e sensibilização ambiental junto à população (Prefeitura Municipal de Candói, 2014).

A seguir serão apresentados os dados referentes à importância da sustentabilidade para a vida profissional e pessoal dos respondentes pesquisados.

A Figura 4 indica que, $61 \%$ dos pesquisados consideram a sustentabilidade muito importante para as suas vidas, tanto no âmbito profissional quanto na sua vida pessoal e, apenas $2 \%$ se mostrou indiferente em relação à sustentabilidade. Isso pode indicar que a população está cada vez mais consciente em relação às mudanças ambientais, ações inseridas por meio da educação ambiental, caracterizando como um exercício de cidadania na busca da qualidade de vida.

Penna (2009, p. 10), ao sintetizar a sustentabilidade pessoal, afirma que "para desenvolver a autoconsciência da sustentabilidade pessoal é preciso considerar os aspectos físicos, emocional, mental e espiritual da nossa vida, que nos leva a buscar informações de muitos campos científicos". Já Reigota (1998), diz que a educação ambiental aponta para propostas pedagógicas centradas na conscientização, mudança

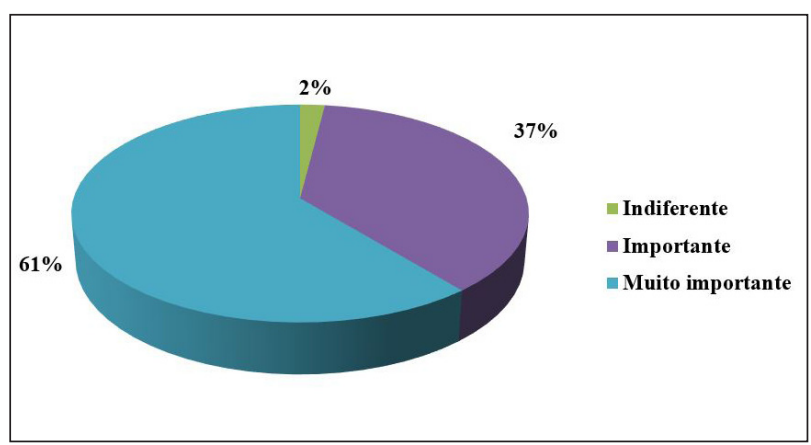

Figura 4 - Importância da sustentabilidade na vida profissional e pessoal Fonte: Elaborado pelos autores com dados coletados na pesquisa de campo (2014).

de comportamento, desenvolvimento de competências, capacidade de avaliação e participação dos educandos.

Para Pádua \& Tabanez (1998), a educação ambiental propicia o aumento de conhecimentos, mudança de valores e aperfeiçoamento de habilidades, condições básicas para estimular maior integração e harmonia dos indivíduos com o meio ambiente.

\section{Análise das dimensões da sustentabilidade}

Esta parte se desdobrou em um conjunto de 37 variáveis, constituídas a partir das dimensões apresentadas no Quadro 2. Inicialmente foi realizada a verificação da existência de dados ausentes e de dados extremos, não sendo identificados dados extremos. Com relação a dados ausentes, um pequeno número de respondentes indicou que não possuíam conhecimento sobre alguns dos aspectos incluídos na pesquisa, no entanto, optou-se por manter os questionários na amostra, utilizando a opção do SPSS de desconsiderar estes nas análises apenas daquelas questões que não foram respondidas. Desta forma a amostra foi composta pelos 59 questionários respondidos, mas variando para menos em algumas das variáveis.

As Tabelas 3 a 8 apresentam a estatística descritiva (média e desvio padrão) das variáveis deste estudo, agrupadas em cada uma das dimensões identificadas na literatura, conforme Quadro 2, bem como a verificação da consistência interna, ou confiabilidade da escala. A consistência interna, ou confiabilidade da escala pode ser verificada pelo Alfa de Cronbach, que é "a medida mais comum de confiabilidade” (Field, 2009, p. 594). 
Tabela 3 - Dimensão política/ institucional

\begin{tabular}{|c|c|c|c|}
\hline Var. & Questão & Média & DP \\
\hline Q14 & Implementação de políiticas públicas espećficas para catadores de resíduos sólidos urbanos & 5,86 & 1,302 \\
\hline Q18 & Constante preocupação do poder público com os catadores autônomos & 5,37 & 1,559 \\
\hline Q27 & Participação efetiva dos serviços públicos municipais no tratamento da coleta seletiva & 5,44 & 1,385 \\
\hline Q32 & Existência do programa cidade limpa & 5,02 & 1,520 \\
\hline Q37 & Existência de uma escala de dias da realização da coleta & 5,28 & 1,453 \\
\hline \multicolumn{2}{|c|}{ Média da dimensão } & 5,08 & 1,345 \\
\hline \multicolumn{2}{|c|}{ Alfa de Cronbach } & \multicolumn{2}{|c|}{0,793} \\
\hline
\end{tabular}

Fonte: Elaborado pelos autores

Tabela 4 - Dimensão tecnológica/estrutural

\begin{tabular}{|c|c|c|c|}
\hline Var. & Questão & Média & DP \\
\hline Q15 & Existência de estrutura física adequada para a separação dos materiais recicláveis & 5,73 & 1,372 \\
\hline Q22 & Existência de estrutura de coleta adequada (caminhões compactadores, tratores, balanças). & 5,61 & 1,387 \\
\hline \multicolumn{2}{|c|}{ Média da dimensão } & 5,52 & 1,378 \\
\hline \multicolumn{2}{|c|}{ Alfa de Cronbach } & \multicolumn{2}{|c|}{0,711} \\
\hline
\end{tabular}

Fonte: Elaborado pelos autores

Tabela 5 - Dimensão ecológica/ambiental

\begin{tabular}{|c|c|c|c|}
\hline Var. & Questão & Média & DP \\
\hline Q01 & Manutenção de lixões; & 5,28 & 1,585 \\
\hline Q02 & Existência de resíduos sólidos urbanos nas vias e terrenos públicos/privados; & 5,28 & 1,664 \\
\hline Q03 & Redução do tempo para liberação do licenciamento ambiental; & 5,40 & 1,374 \\
\hline Q04 & Ocorrência contumaz de contaminação de solo e/ou água com produtos tóxicos; & 5,20 & 1,344 \\
\hline Q16 & Fiscalização ambiental regular; & 5,25 & 1,316 \\
\hline Q17 & Efetiva aplicaçã̃o da legislação ambiental; & 5,53 & 1,432 \\
\hline \multicolumn{2}{|c|}{ Média da dimensão } & 5,21 & 1,186 \\
\hline \multicolumn{2}{|c|}{ Alfa de Cronbach } & \multicolumn{2}{|c|}{0,830} \\
\hline
\end{tabular}

Fonte: Elaborado pelos autores.

Tabela 6 - Dimensão econômica/financeira

\begin{tabular}{|c|c|c|c|}
\hline Var. & Questão & Média & DP \\
\hline Q07 & Promoç̣̃o da geracação de renda familiar por meio da coleta de resíduos sólidos urbanos (catadores de lixo) & 5,31 & 1,477 \\
\hline Q28 & $\begin{array}{l}\text { Incentivo a empregabilidade sustentável - desenvolvimento profissional sustentável, capaz se adaptar conforme as } \\
\text { necessidades do mercado. }\end{array}$ & 4,85 & 1,533 \\
\hline \multicolumn{2}{|c|}{ Média da dimensão } & 5,09 & 1,363 \\
\hline \multicolumn{2}{|c|}{ Alfa de Cronbach } & \multicolumn{2}{|c|}{0,711} \\
\hline
\end{tabular}

Fonte: Elaborado pelos autores. 
Tabela 7 - Dimensão da inclusão social

\begin{tabular}{|c|c|c|c|}
\hline Var. & Questão & Média & DP \\
\hline Q12 & Busca por melhores condições de trabaha nas atividades dos catadores de resíduos sólidos urbanos & 5,84 & 1,242 \\
\hline Q13 & Promocãa da valorização social das atividades desempenhadas pelos catadores resíduos sólidos urbanos & 5,49 & 1,424 \\
\hline Q19 & Constante preocupaç̦o do poder público com a cadeia produtiva informal & 5,24 & 1,640 \\
\hline Q20 & Existência de incentivo cos catadores em manter os filhos na escola & 4,67 & 1,567 \\
\hline Q30 & Existência de acçoes sociais envolvendo a comunidade acadêmica & 5,33 & 1,414 \\
\hline Q34 & Adesão da população as açōes de sustentabilidade & 5,02 & 1,500 \\
\hline \multicolumn{2}{|c|}{ Média da dimensão } & 5,05 & 1,363 \\
\hline \multicolumn{2}{|c|}{ Alfa de Cronbach } & \multicolumn{2}{|c|}{0,875} \\
\hline
\end{tabular}

Fonte: Elaborado pelos autores.

Tabela 8 - Dimensão do conhecimento e da cultura

\begin{tabular}{|c|c|c|c|}
\hline Var. & Questão & Média & DP \\
\hline Q05 & Promoção de campanhas envolvendo açōes de sustentabilidade & 5,31 & 1,641 \\
\hline Q06 & Separaç̣ão correta do lixo nas residências e instituvições & 5,86 & 1,353 \\
\hline Q08 & Crescente aquisiç,ão de produtos com embalagem sustentável & 5,46 & 1,633 \\
\hline Q09 & Capacidade da população na reutilização de embalagens sustentáveis & 5,26 & 1,462 \\
\hline Q10 & $\begin{array}{l}\text { Promoccão de compras conscientes, evitando compras que gerem lixo orgânico (vencimento do prazo de validade ou } \\
\text { desperdícios) }\end{array}$ & 5,09 & 1,463 \\
\hline Q11 & Busca pela ampliação na capacidade de reciclar embalagens & 5,54 & 1,442 \\
\hline Q21 & Promoção do reaproveitamento do lixo orgânico na própria residência & 5,51 & 1,483 \\
\hline Q24 & Promoç̃o de Açōes Sociais envolvendo a coleta seletiva & 5,69 & 1,255 \\
\hline Q25 & Promoção de programas educativos continuados voltados à sustentabilidade & 5,51 & 1,422 \\
\hline Q26 & Promoção de atividades envolvendo a população no processo de conscientizacạ̃o & 5,43 & 1,399 \\
\hline Q29 & Existência de ações de sustentabilidade voltadas à gestão cultural & 4,97 & 1,361 \\
\hline Q31 & A cultura da população já está adepta a sustentabilidade & 4,37 & 1,646 \\
\hline Q33 & Promoção de palestras educativas nas escolas & 5,09 & 1,292 \\
\hline Q35 & Constante capacitação dos coletores & 4,91 & 1,380 \\
\hline Q36 & Orientação à população quanto a separaç̧̃o dos materiais recicláveis & 5,29 & 1,384 \\
\hline \multicolumn{2}{|c|}{ Média da dimensão } & 5,07 & 1,285 \\
\hline \multicolumn{2}{|c|}{ Alfa de Cronbach } & \multicolumn{2}{|c|}{0,942} \\
\hline
\end{tabular}

Fonte: Elaborado pelos autores.

Segundo Field (2009, p. 594), "um valor de 0,7-0,8 é aceitável para o $\alpha$ de Cronbach e valores substancialmente mais baixos indicam uma escala não confiável". Para Malhotra (2006, p. 277), o valor esperado de confiabilidade é no mínimo 0,6 , sendo que valores inferiores podem indicar uma consistência interna insatisfatória.
A Tabela 3, que se refere à dimensão política/ institucional, mostra que a relação entre a menor e a maior média é de 0,84 . 0 valor encontrado referente ao $\alpha$ de Cronbach $(0,793)$ demonstra confiabilidade. Desta maneira, é possível supor que esta dimensão acontece de maneira satisfatória no município estudado. 
A Tabela 4, que se refere à dimensão tecnológica/ estrutural, mostra que a relação entre a menor e a maior média é de 0,12. 0 valor encontrado referente ao $\alpha$ de Cronbach $(0,711)$ demonstra confiabilidade. Desta maneira, é possível supor que esta dimensão acontece de maneira satisfatória no município estudado.

A Tabela 5, a qual faz referência à dimensão ecológica/ambiental, mostra que a relação entre a menor e a maior média é de 0,33 . 0 valor encontrado referente ao $\alpha$ de Cronbach $(0,830)$ demonstra confiabilidade. Desta maneira, é possível supor que esta dimensão inicia-se pelas escolas e a dimensão ambiental representa a possibilidade de lidar com conexões entre diferentes dimensões humanas, propiciando entrelaçamentos e múltiplos trânsitos entre múltiplos saberes. A escola participa então dessa rede "como uma instituição dinâmica com capacidade de compreender e articular os processos cognitivos com os contextos da vida" (Tristão, 2002).

Por isso, a educação ambiental é transpassada por vários campos de conhecimento, o que a situa como uma abordagem multireferencial, e a complexidade ambiental, (Leff, 2001) refletindo um tecido conceitual heterogêneo, "onde os campos de conhecimento, as noções e os conceitos podem ser originários de várias áreas do saber" (Tristão, 2002).

A Tabela 6, que faz referência à dimensão econômica/financeira, mostra que a relação entre a menor e a maior média é de 0,46 . 0 valor encontrado referente ao $\alpha$ de Cronbach $(0,711)$ demonstra confiabilidade. Desta maneira, é possível supor que esta dimensão revela-se satisfatória, mas com a questão relacionada ao incentivo, a empregabilidade sustentável ligeiramente abaixo das médias das variáveis até aqui apresentadas.

A Tabela 7 apresenta os dados relacionados à dimensão da inclusão social. A média apresenta uma variação de 1,17 quando comparadas a maior em relação à menor. Já o $\alpha$ de Cronbach encontrado, no valor de 0,875 demonstra que o resultado encontrado pode ser considerado fidedigno. Nesta dimensão se encontra uma variável com menor média de todas as analisadas, indicando um aspecto ainda incipiente em comparação com os demais.

Desta maneira, é possível inferir que as ações de sustentabilidade, relacionadas à inclusão social, podem ser visualizadas como um fator de impacto no desempenho do município. Ou seja, a valorização destas atividades pode favorecer o desenvolvimento do município tornando-se, consequentemente, um recurso das ações de incentivo da valorização social que pode ser utilizado de maneira favorável ao desenvolvimento da comunidade.

A participação social contemporânea está no mesmo nível em relação à educação ambiental, onde o principal eixo de atuação da educação ambiental deve buscar, acima de tudo, a solidariedade, a igualdade e o respeito à diferença por meio de formas democráticas de atuação baseadas em práticas interativas e dialógicas. Isto se consubstancia no objetivo de criar novas atitudes e comportamentos diante do consumo na nossa sociedade e de estimular a mudança de valores individuais e coletivos (Jacobi, 1997).

A Tabela 8 apresenta os dados relacionados à dimensão do conhecimento e da cultura. A média apresenta uma variação de 1,49 quando comparadas a maior em relação à menor. Já o $\alpha$ de Cronbach encontrado no valor de 0,942 revela que o resultado descoberto pode ser considerado positivo. Nesta dimensão é que se encontra a variável com a menor média entre todas as variáveis, a que está relacionada à cultura da população em relação a sustentabilidade.

A verificação do Alfa de Cronbach, a partir do SPSS, também permite a verificação da existência de variáveis que poderiam ser retiradas (excluídas) das análises para melhorar o valor do alfa. No entanto, os resultados apresentados não indicaram a necessidade de exclusão de nenhuma variável.

0 passo seguinte na análise dos dados consiste na verificação do perfil dos respondentes quanto à sua percepção da sustentabilidade, a partir dos seis construtos (dimensões) da mesma. Para isso utilizou-se a Análise de Cluster, que "é uma técnica exploratória de análise multivariada que permite agrupar sujeitos ou variáveis em grupos homogêneos ou compactos relativamente a uma ou mais características comuns" (Maroco, 2003, p. 295). Hair Jr. et al. (2005, p. 401) destacam que a "análise de conglomerados tenta identificar agrupamentos naturais usando diversas variáveis".

O resultado da Análise de Cluster, utilizando o Método de Ward para o agrupamento das variáveis e a Distância Euclidiana Quadrada como medida de semelhança e distância, indicou que as variáveis se agrupam em dois conjuntos. A verificação dos agrupamentos indicou que os dois grupos apresentam percepções distintas em cada uma das dimensões, conforme pode ser observado na Figura 5 e na Tabela 9. 
Na Figura 5 é visível a diferença entre os dois agrupamentos, denominados de Otimistas e Pessimistas, em função da média de suas percepções em cada uma das dimensões da sustentabilidade. Otimistas porque as médias foram elevadas e indicam uma percepção positiva em relação às práticas/ações existentes no município no sentido de promover a sustentabilidade. Pessimistas porque as médias foram significativamente inferiores em relação às médias do outro agrupamento.

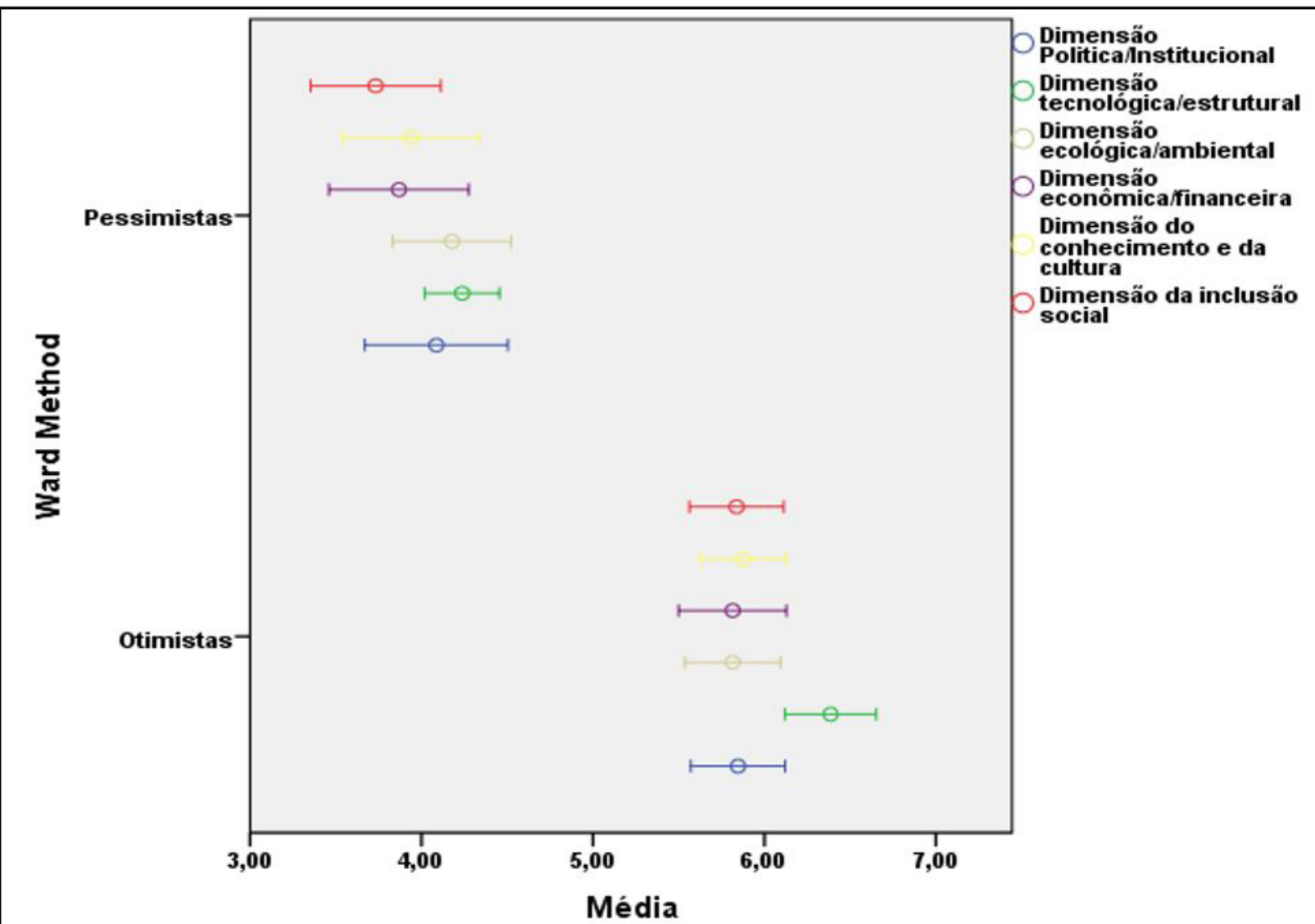

Barras de erro: $95 \% \mathrm{Cl}$

Figura 5 - Agrupamentos obtidos a partir da Análise de Cluster Fonte: Saída do SPSS.

Tabela 9 - Média das dimensões por agrupamento

\begin{tabular}{lcccc}
\hline & \multicolumn{2}{c}{ Agrupamentos } & & \\
\cline { 2 - 4 } \multicolumn{1}{c}{ Dimensão } & $\begin{array}{c}\text { Otimistas } \\
\mathbf{n = 3 5}\end{array}$ & $\begin{array}{c}\text { Pessimistas } \\
\mathbf{n = 1 9}\end{array}$ & $\boldsymbol{t}$ & Sig. \\
\hline Política/Institucional & 5,85 & 4,09 & 7,489 & $0,000^{\star}$ \\
Tecnológica/Estrutural & 6,39 & 4,24 & 12,834 & $0,000^{\star}$ \\
Ecológica/Ambiental & 5,81 & 4,18 & 7,342 & $0,000^{\star}$ \\
Econômica/Financeira & 5,81 & 3,87 & 7,647 & $0,000^{\star}$ \\
Do Conhecimento e da Cultura & 5,88 & 3,94 & 8,551 & $0,000^{\star}$ \\
Da Inclusão Social & 5,84 & 3,73 & 9,280 & $0,000^{\star}$ \\
\hline
\end{tabular}

* Significância an nivel de 0,05. Fonte: Elaborado pelos autores. 
A Tabela 9 apresenta as médias e também o comparativo da significância da diferença entre os agrupamentos a partir do Teste t para amostras independentes, que também é chamado teste $t$ de medidas independentes (Field, 2009, p. 279), e é utilizado, como afirma Maroco (2003, p. 122), "para testar se as médias de duas populações são ou não significativamente diferentes".

Assim, foram identificados alguns dos aspectos da sustentabilidade na gestão municipal de resíduos sólidos, verificando que existem entre os respondentes dois grupos com percepções distintas sobre estes aspectos.

No primeiro grupo, denominado de otimistas, as médias são elevadas e equitativas, exceto para a dimensão Tecnológica/Estrutural onde a média é ligeiramente maior. Já no caso do segundo grupo, denominado de pessimistas, as medidas são significativamente mais baixas e ligeiramente diferentes entre si, indicando que a percepção destes tende a ser superior em alguns aspectos e inferior em outros. Cabe destacar que, também neste último grupo, a dimensão Tecnológica/Estrutural obteve a maior média, indicando que também este grupo percebe a relevância desta dimensão em relação às demais. No entanto, este grupo apresentou a menor média na dimensão da Inclusão Social.

A partir desta última consideração é possível supor que este seja um dos aspectos da sustentabilidade na gestão municipal de resíduos sólidos do município que ainda não estão perfeitamente alinhados com as demais dimensões ou que talvez estejam alinhados, mas ainda não seja do conhecimento de toda população, limitando a amostra.

Visto que os indicadores são instrumentos que permitem aferir a distância entre a situação atual da sociedade e seus objetivos de desenvolvimento, além de oferecer suporte à formulação de práticas e políticas (Guimarães \& Feichas, 2009) é fundamental que os indicadores possuam características como simplicidade, analiticamente válido, apto a usar os dados existentes, possuir custo-efetivo, além de ser de fácil entendimento (Carvalho, 2006), ou seja, os indicadores devem ser adaptados à realidade de cada região e, também, avaliados de maneira constante, para que sejam aprimorados tornando-se, cada vez mais, eficazes.

Não foram identificados estudos que tratassem da questão da sustentabilidade na gestão municipal em municípios de pequeno porte, apenas em municípios de grande porte, no caso, Curitiba e Florianópolis (Meza, et al., 2013; Domingos \& Boeira, 2015). Além disso, não foram identificados estudos que adotassem a mesma metodologia (coleta de dados por meio de questionário, composição do questionário, técnicas estatísticas para análise dos dados e foco/amostra) para que fosse possível comparar os resultados.

No entanto, foi localizado um estudo relacionado à gestão de resíduos sólidos urbanos, realizado por Ferreira \& Ferreira (2008), que objetivava avaliar os danos ambientais decorrentes da forma de disposição dos Resíduos Sólidos Urbanos em Cachoeira Dourada, em Minas Gerais, e mostrar os reflexos negativos para o turismo e, consequentemente, para à população local. Percebe-se que o tratamento dado aos resíduos sólidos desse município acontecia de maneira inadequada e em desconformidade com a legislação ambiental vigente. Observou-se, também, nesta pesquisa, que o manejo correto e tratamento posterior estariam ocorrendo somente quando se referia aos resíduos sólidos do serviço de saúde (Ferreira \& Ferreira, 2008).

Então, ao realizar um paralelo entre os resultados obtidos neste estudo e o resultado do único estudo identificado, apesar das características distintas de cada um deles, percebe-se que, independente do município, não somente é necessário o comprometimento da gestão municipal, mas também de toda a sociedade para que os resultados sejam positivos, gerando maior qualidade de vida aos cidadãos.

Todavia, salienta-se que esta pesquisa não teve o intuito de responder a todas as questões no que se refere à gestão de resíduos sólidos municipais e ações de sustentabilidade existentes. Ainda, destaca-se que a amostra é pequena, dificultando as análises quantitativas. Por isso, as realizações de novas pesquisas nesta temática aprofundariam os estudos, podendo, assim, identificar a realidade de distintos municípios e/ou regiões brasileiras.

\section{Considerações finais}

O objetivo proposto para este estudo de identificar e analisar aspectos da sustentabilidade na gestão municipal de resíduos sólidos em um município do Centro Oeste do Paraná pode ser considerado cumprido.

Por meio da análise dos dados obtidos nesta pesquisa, verificou-se que existem diferentes percepções sobre 
as seis dimensões (política/ institucional, tecnológica/ estrutural, ecológica/ambiental, econômica/financeira, inclusão social e conhecimento e cultura) estudadas.

Por tratar-se de uma pesquisa aplicada a uma determinada amostra, este estudo limita-se devido à falta de instrumentalização de resultados gerais. No entanto, torna-se possível supor que a gestão municipal de resíduos sólidos, alinhada às ações de sustentabilidade pode favorecer o desenvolvimento do município. Por isso, é fundamental dispor os aspectos da sustentabilidade na gestão municipal de resíduos sólidos do município com as demais dimensões, gerando o conhecimento de toda população.

Visto pelo lado dos responsáveis, em relação às ações de sustentabilidade que o município desenvolveu, observa-se que as visões coincidem, haja vista que o município continua investindo em políticas públicas relacionadas às ações de sustentabilidade e gestão de resíduos sólidos municipais.

Este estudo é inovador por propor uma sistemática específica de coleta de dados para verificar aspectos relacionados à sustentabilidade na gestão municipal, tanto em termos de instrumento de coleta de dados quanto em termos de análise dos mesmos, colocando-se assim como um ponto de partida para futuros estudos. Contudo, como limitação desta pesquisa aponta-se o fato de ser contextualizada em âmbito municipal, trazendo resultado apenas no contexto no qual o município se situa.

Como proposta para pesquisas futuras, sugere-se o desenvolvimento de estudos nesta temática em outros municípios com vistas à comparabilidade dos resultados. Sugere-se, ainda, que seja analisada a viabilidade econômica do tratamento de resíduos no município. E, devido ao fato de existirem grupos com percepções distintas sobre o tema, sugere-se que o estudo aplique-se a uma amostra que abranja diversas glebas populacionais, fomentando, assim, as ações de sustentabilidade no município para que sejam de conhecimento de toda a população.

\section{Referências}

Agamuthu, P., Khidzir, K. M. \& Fausiah, S. H. (2009). Drivers of sustainable waste management in Asia. Waste Management and Research, (27), 625-633.

Andion, C. (2012). Ação administrativa, racionalidade e gerência na nova esfera pública. In: A. Philippi Jr., C. A.
C. Sampaio, \& V. Fernandes. Gestão da natureza pública e sustentabilidade (1 $1^{\mathrm{a}}$ ed., p. 33-56). Barueri: Manole.

Barbieri, J. C. (2007). Gestão ambiental empresarial: conceitos, modelos e instrumentos. (2.ed. atual e ampliada). São Paulo: Saraiva.

Barbieri, J. C., Vasconcelos, I. F. G. de, Andreassi, T. \& Vasconcelos, F. C. de. (2010). Inovação e sustentabilidade: novos modelos e proposições. Revista de Administração de Empresas - RAE, 50 (2), 146-154.

Botelho, D. \& Zouain, D. M. (Orgs.). (2009). Pesquisa quantitativa em Administração. (1 ed.). São Paulo: Atlas.

Decreto nํ 7.217, 21 de junho de 2010 (2010). Regulamenta a Lei $n^{\circ} 11.445$, de 5 de janeiro de 2007, que estabelece diretrizes nacionais para o saneamento básico, e dá outras providências. Brasília.

Candler, G. \& Dumont, G. (2012). Responsabilidade cívica na sustentabilidade da sociedade e o papel dos governos. In: A. Philippi Jr., C. A. C. Sampaio, \& V. Fernandes. Gestão da natureza pública e sustentabilidade (1 ed., p. 91-116). Barueri, SP: Manole.

Carvalho, P. G. M de. (2006). Indicadores Ambientais para Gestão Municipal. ENCE-IBGE.

Collis, J. \& Hussey, R. (2005). Pesquisa em administração: um guia prático para alunos de graduação e pós-graduação. (2 ${ }^{\mathrm{a}}$ ed.). Porto Alegre: Bookman.

Cooper, D. R. \& Schindler, P. S. (2011). Métodos de Pesquisa em Administração. (10 a ed.). Porto Alegre: Bookman.

Corrêa, C. C., Liston, R. F., Barbosa, A. C., Silva, C. P. \& Barczsz, S. (2010). Gestão pública e desenvolvimento sustentável: a importância da implantação de plano diretor no ato de criação de um município. In: Congresso SOBER - Sociedade Brasileira de Economia, Administração e Sociologia Rural: Tecnologia, Desenvolvimento e Integração social. Maringá, 48.

Daly, H. (1973). Toward a Steady State Economy. San Francisco: Freeman.

Dias, S. M. F. (2003). Avaliação de programas de educação ambiental voltados para o gerenciamento os resíduos sólidos urbanos. (Tese de doutorado). Faculdade de Saúde Pública, Universidade de São Paulo, São Paulo.

Domingos, D. de C. \& Boeira, S. L. (2015). Gerenciamento de resíduos sólidos urbanos domiciliares: análise do atual cenário no município de Florianópolis. Revista de Gestão Ambiental e Sustentabilidade-GeAS, 4(3), 14-30. 
Elkington, J. (2001). Canibais com garfo e faca. São Paulo: Makron Books.

Ferreira, S. de L. \& Ferreira, O. M. (2008). Diagnóstico e proposta de um modelo de gerenciamento de resíduos sólidos urbanos para o município de Cachoeira Dourada Minas Gerais. (Produção acadêmica). Programas de graduação engenharia ambiental, Pontifícia Universidade Católica de Goiás, Goiás.

Field, A. (2009). Descobrindo a estatística usando o SPSS. ( $2^{\mathrm{a}}$ ed.) Porto Alegre: Artmed.

Furiam, S. M. \& Günther, W. R. (2006). Avaliação da educação ambiental no gerenciamento dos resíduos sólidos no campus da Universidade Estadual de Feira de Santana. Sitientibus, (35), 7-27.

Goodland, R. (1995). The concept of environmental sustainability, Aun. Rev. Ecol. Syst. (26), 1-24.

Guimarães, R. P. \& Feichas S. A. Q. (2009). Desafios na Construção de Indicadores de Sustentabilidade. Ambiente \& Sociedade, 12(2).

Hair Jr., J.F., Babin, B., Money, A.H. \& Samouel, P. (2005). Fundamentos de métodos de pesquisa em administração. Porto Alegre: Bookman.

Instituto Brasileiro de Geografia e Estatística - IBGE (2015). Síntese de informações de Candói - PR. Recuperado em 28 de dezembro de 2015, dewww.cidades.ibge.gov.br/xtras/ perfil.php?lang $=\&$ codmun $=410442 \&$ search $=||$ infogr $\% E 1$ fico:-informa\%E7\%F5es-completas

Instituto Paranaense de Desenvolvimento Econômico e Social - Ipardes (2015). Caderno estatístico município de Candói. Recuperado em 27 de dezembro de 2015, de www.ipardes.gov.br/cadernos/MontaCadPdf1. php?Municipio $=85140 \&$ btOk $=0 \mathrm{k}$

Iucn. (1980). The World Conservation Strategy. Gland: Switzerland.

Jacobi, P. (1997). Meio ambiente urbano e sustentabilidade: alguns elementos para a reflexão. In: C. Cavalcante (org.). Meio ambiente, desenvolvimento sustentável e políticas públicas. (384-390). São Paulo: Cortez.

Leff, E. (2001). Epistemologia ambiental. São Paulo: Cortez.

Maia, P. L. (2007). Introdução à ética e responsabilidade social: administração e ciências contábeis. São Paulo: Liv. e Ed. Universitária de Direito.

Malhotra, N. K. (2006). Pesquisa de Marketing: uma orientação aplicada. (4a ed.). Porto Alegre: Bookman.
Maroco, J. (2003). Análise estatística - com utilização do SPSS. (2ª ed.) Lisboa: Edições Sílabo.

Martínez, R. Q. (2006). Indicadores de Sustentabilidad: experiencia mundial y desafíos parra América Latina. Consultora CEPAL.

Meza, M. L. F. G., Oliverira, M. F. B. G. \& Vasconcelos, M. C. (2013). 0 papel do município na gestão de resíduos sólidos: programas e projetos de prefeitura de Curitiba. In: I Seminário nacional de planejamento e desenvolvimento. Universidade Tecnológica Federal do Paraná, Curitiba.

Mill, J. S. (1876). Principles of Political Economy, London.

Moraes, L. R. S., \& Borja, P. C. (2003). Indicadores de Saúde Ambiental com enfoque para área de Saneamento. Parte 1 - Aspectos Conceituais e Metodológicos. Engenharia Sanitária e Ambiental, 8(1),13-25.

Oliveira, J. A. P. de. (2008). Empresas na sociedade: sustentabilidade e responsabilidade social. Rio de Janeiro: Elsevier.

Pádua, S. \& Tabanez, M. (orgs.). (1998). Educação ambiental: caminhos trilhados no Brasil. São Paulo: Ipê.

Penna, L. (2009). A sustentabilidade. Recuperado em 15 de janeiro de 2015, de http://lucypenna.com

Pereira, C. M. S. S. (2010). Gestão sistêmica de resíduos sólidos para a UEFS: subsídios para a construção de uma política participativa. (Dissertação de mestrado). Programa de PósGraduação em Engenharia Civil e Ambiental, Universidade Estadual de Feira de Santana, Feira de Santana.

Polaz, C. N. M. \& Teixeira, B. A. do N. (2009). Indicadores de sustentabilidade para a gestão municipal de resíduos sólidos urbanos: um estudo para São Carlos (SP). Engenharia Sanitária e Ambiental.14(3), 411-420.

Philippi Jr., A., Sampaio, C. A. C.\& Fernandes, V. (2012). Gestão da natureza pública e sustentabilidade. Barueri, SP: Manole.

Philippi Jr., A.,Oliveira e Aguiar A. de, Castilhos Jr., A. B., Luzzi, D. A. Gestão integrada de resíduos sólidos. In: A. Jardim, C. Yoshida, \& J. V. Machado Filho. (2012). Política nacional, gestão e gerenciamento de resíduos sólidos ( $\mathrm{p}$. 229-244). Barueri: Manole.

Prefeitura Municipal de Candói. (2014). Portal da transparência. Recuperado em 5 de dezembro de 2014, de www.candoi.pr.gov.br/transparencia.php

Reigota, M. (1998). Desafios à educação ambiental escolar. In: Cascino, F., Jacobi, P \& Oliveira, J. F. de. (orgs.). Educação, 
meio ambiente e cidadania: reflexões e experiências (p. 4350). São Paulo: SMA.

Reis, L. B., Fadigas, E. A. A., \& Carvalho, C. E. (2005). Energia, recursos naturais e a prática do desenvolvimento sustentável. Barueri: Manole.

Rodrigues, W. \& Santana, W. C. (2012). Análise econômica de sistemas de gestão de resíduos sólidos urbanos: o caso da coleta de lixo seletiva em Palmas, TO. Revista de Gestão Urbana. 4(2), 299-312.

Santiago, L. S. \& Dias, S. M. F. (2010). Gerenciamento de resíduos sólidos em municípios brasileiros: uma análise de sua sustentabilidade. In: Simpósio Ítalo-Brasileiro de Engenharia Sanitária e Ambienta. Rio de Janeiro: ABES.
Singer, P. (2002). A recente ressurreição da economia solidária no Brasil. In: B. de S. Santos (Org.) Produzir para viver: os caminhos da produção não capitalista (p. 81-126). Rio de Janeiro: Civilização Brasileira.

Yin, R. K. (2010). Estudo de Caso: planejamento e métodos. (4⿳亠口了 ed.). Porto Alegre: Bookman.

Tristão, M. As dimensões e os desafios da educação ambiental na sociedade do conhecimento. In: A. Rusheinsky (org.). (2002). Educação ambiental: abordagens múltiplas (p.169-173). Porto Alegre: Artmed.

Recebido: Set. 10, 2015

Aprovado: Abr. 05, 2016 